\title{
Fostering regional development in eastern Macedonia and Thrace, Greece, through road transport projects
}

\author{
Christina Mavraki ${ }^{1}$, Garyfallos Arabatzis ${ }^{2}$, Apostolos Kantartzis ${ }^{3 *}$ \& Chrisovalantis \\ Malesios $^{4}$
}

${ }^{1}$ Department of Forestry and Management of the Environment and Natural Resources, Democritus University of Thrace, 193 Pantazidou St., Orestiada, Greece, email: xmavraki@gmail.com

${ }^{2}$ Department of Forestry and Management of the Environment and Natural Resources, Democritus University of Thrace, 193 Pantazidou St., Orestiada, Greece, email: garamp@fmenr.duth.gr

${ }^{3}$ Department of Forestry and Management of the Environment and Natural Resources, Democritus University of Thrace, 193 Pantazidou St., Orestiada, Greece, email: apkantar@fmenr.duth.gr *Corresponding author

${ }^{4}$ Operations \& Information Management Department, Aston Business School, Aston University, Birmingham, UK, email: c.malesios@aston.ac.uk 


\begin{abstract}
The purpose of the paper is to evaluate the extent to which the road transport projects implemented within the Greek National Strategic Reference Framework (NSRF) 2007-2013 contributed to the economic development of eastern Macedonia and Thrace, Greece. These projects were included in the respective regional operational programs co-financed by the European Union (EU) and national funds. The paper discusses the EU's regional and cohesion policy which aims at reducing regional inequalities and ensuring social, economic and territorial cohesion. In Greece, cohesion policy implementation for the 2007-2013 period was achieved through the NSRF, 2007-2013, whose training philosophy and the priorities that it set are the focus of the present study. The research area concerns the region of eastern Macedonia and Thrace and, more specifically, the 21 municipalities that it consists of. One of the main conclusions of the study is that public expenditure on the projects is directly associated with the area covered by the municipalities, as well as with the length of the road network improved. However, no correlation with the population of municipalities or the gross domestic product (GDP) of each regional unit has been observed. Our findings suggest that decisions for efficient allocation of infrastructure resources in a region by policy makers should not be based on single characteristics such as regional population density, but rather on more complex considerations, such as existing natural resources, geomorphological characteristics and location.
\end{abstract}

Keywords: regional development; regional policy; regional inequalities; operational program for eastern Macedonia and Thrace.

\title{
1. Introduction
}

Regional inequalities that occur are mostly in the form of unequal social and economic opportunities, as well as marked disparities in prosperity levels among regions. Such inequalities are the main reasons for the exercise of the EU's regional policy, the key component of which is cohesion policy. Through this, the EU transfers resources from wealthier to poorer areas with the ultimate goal of reducing backwardness in the least developed regions. 
The creation of infrastructure is the most important policy capable of contributing to the development of regions which are characterized by lagged performance in various sectors. Greater emphasis should be given to the construction of transport infrastructures connecting cities and regions with the development centers of a country, given such interventions have proven to boost quality of life and economic efficiency. The upgrading and proper maintenance of road networks is bound to impact a country's economic and social well-being. Indeed, economic growth and prosperity are directly related to issues of regional convergence and reduction of isolation in remote, less favored and low potential areas.

The NSRF 2007-2013 constitutes the reference document for the programming of EU funds at the national level for the 2007-2013 period. It was elaborated within the framework of the new strategic approach to the cohesion policy of the EU and sets out the investment priorities for the regional and sectoral programs to be supported by the EU over the seven-year period 2007-13. The Greek NSRF for 2007-2013 consisted of 5 regional operational programs (ROPs), 8 sectoral and 12 European territorial cooperation programs. The programs are designed to support the modernization and diversification of national and regional economies, improve competitiveness and underpin efforts to maintain macroeconomic stability. To that end, a number of road transport projects were created in the 2007-13 period, with a view to promoting effective mobility solutions.

The aim of the current paper is to assess how and in which specific fields, the actions accomplished within the framework of the NSRF 2007-2013 contributed to the development of a Greek region. The region chosen for this study is eastern Macedonia and Thrace (R.E.M.\&T.) - which constitutes a typical example of a spatial entity well-distanced from the country's economic and governmental centers. These actions were incorporated into the corresponding ROP for 2007-2013 of eastern Macedonia and Thrace which included, inter alia, 87 road transport projects. The obtained results contain findings which can be used to create proposals to policy makers for future spatially targeted interventions regarding investments in transport infrastructure projects. Such interventions are designed to achieve efficient allocation and distribution of infrastructure resources within a region. Furthermore, based on the conclusions of the present research, a number of policy implications can be drawn for the better management of inputs in regional finance programs such as the NSRF 2007-2013. 


\section{Literature review}

Regional development is the provision of assistance to regions which are less economically developed in order to promote their balanced economic and social growth. In the EU, it is treated as an integral factor in state economic and social policy (Antonescu, 2014).

Dealing with regional inequalities has evolved into an important issue for EU policy. Although several studies indicate that there is evidence of a degree of convergence within the EU at the country level, this is not always the case at regional level. The uneven development has a significant impact on the stability of countries, social relationships and the effective utilization of economic resources (Goletsis and Chletsos, 2011).

The research by Petrakos and Economou (2014) reveals that southeastern Europe is characterized by a growing regional imbalance, the increasing strengthening of metropolitan regions and by serious discontinuities at their borders, which, in most cases, are a product of isolated border areas. Urban systems with serious deficiencies in medium-sized cities are also a characteristic of southeastern Europe.

Due to these considerable differences in regional development, the EU has adopted a set of policy measures in order to promote the integration and convergence of less developed areas among the member states, by applying the so-called cohesion policy (Mikulic et al., 2013). Reasons for these differences can be found in contrasts between eastern and western parts of Europe, as well as between north and south Europe. In general, the central, western and northern regions are more developed than the eastern and southern areas. The majority of developed EU regions are to be found in the group of western European countries starting with the UK, passing through Germany and Switzerland and ending in northern Italy. At the opposite end of this spectrum are the peripheral districts and communities of the EU whose development is lagging behind. These districts which have failed to reach the development levels of northern regions are located in Greece, Portugal, Spain and southern Italy. It is worth noting that the more developed EU regions are approximately eight times richer than their less developed counterparts.

According to Tvrdon (2012), the EU is a heterogeneous integration, with major economic and social differences among member states and their regions. 
Therefore, the foremost challenge for EU cohesion policy is to acquire the required power and to increase financial resources in order to combat inefficiency, gaps and exclusion in all European regions (Petrakos, 2012).

However, the effectiveness of EU cohesion policy has been strongly criticized, especially by some wealthier member states (Hoerner and Stephenso, 2012). Begg (2010) has termed the European cohesion policy as "a policy searching for objectives" and highlights the confusion generated by different, often competing and incompatible objectives. To be effective, it is imperative that this policy encourage targeted interventions that will appropriately respond to identified regional needs, and have a coherent design based on coordination and balance of approaches including both top-down and bottom-up methods (Dontigney, 2017; Monastiriotis et al., 2017).

The existence of regional inequalities in a country remains an important theoretical and practical issue to be considered when planning and allocating resources and capital (Goletsis and Chletsos, 2011). What influences growth in Greece during the last decades is the country's metropolitan structure. In particular, the two largest urban centers, Athens and Thessaloniki, account for almost half of the country's population and productive activities that far exceed the proportion of their population. This inequality in the distribution of the population is a result of strong internal migration flows and the abandonment of rural and hard-to-reach provinces during the greater part of the post-war period (Petrakos, 2004). In addition, new factors that exhibit an important effect on this type of metropolitan concentration are those associated with the increasing globalization of economic activities and the integration of the European market. As well, the structural changes taking place in the production and economic cycles are also an important factor (Petrakos and Tsoukalas, 2004). A direct consequence is the unequal allocation of infrastructures, services and development opportunities (see, e.g., Polyzos, 2011). Another feature of the regional problem in Greece is the depopulation of the rural regions and the lack of mediumsized urban centers. Since the early 60's a large number of small and medium-sized cities have witnessed declining trends in their population. This internal migration in Greece has its roots in the post Second World War period when large-scale economic transformations occurred, characterized by the shrinkage of the primary, as well as the growth of the secondary and, subsequently, the tertiary sector. These changes were accompanied by population movements from rural to urban areas, increased urbanization and the rapid expansion of the country's largest urban centers. 
In order to tackle Greece's 'regional problem' and promote development at the regional/local level, a number of large-scale projects - mainly in transport infrastructure - have been carried out in specific regions over the last decades.

Investing in transport infrastructure has had a positive impact on economic growth, generating wealth and jobs, boosting trade, contributing to geographical accessibility and facilitation of people's mobility. Transport infrastructure has long been and still remains, the cornerstone of the EU's and other countries' regional development policies (Crescennzi and Rodriguez-Pose, 2012). Ever since the EEC Treaty, the EU has sought a common transport policy mainly for land transport due to the need to simultaneously unify transportation of people and goods (Hadjiioannou, 2015). The integration of the European network favors territorial cohesion, international cooperation and the competitiveness of EU (European Commission, 2011). Moreover, it is clear that the role of road infrastructure in tourism development of the regions is of paramount importance as their accessibility and attractiveness increases (Rolfe and Flint, 2018).

According to Aschauer (1989), differences in the stock of public infrastructure are the basis of differences in productivity, national production and ultimately development. Countries with the highest public infrastructure stocks also have a higher private sector activity. According to Biehl (1991), infrastructure improvements have a direct impact on productivity as well as on labor costs.

Overall then, transport infrastructure is an effective tool to promote economic growth, increase accessibility, reduce regional disparities (Rietveld 1994; Stelder, 2016; Vickerman et al. 1999), and also fuel productivity of the regional economy (Zhang and Shengao, 2019). Privatization of public infrastructure was initiated some decades ago (Fallon, 1997), accompanied by the involvement of the private sector in the construction and operation of road systems (Skagiannis and Kaparos, 2013). In particular, improvement of road infrastructure in Italy has reduced the travel time between regions and increased accessibility to remote areas (Cosci and Mirra, 2018), while facilitating access to labor markets in Turkey (Akyelken, 2015) and the Netherlands (Moya-Gomez and Geurs, forthcoming). In Spain, upgrades in the road network have had a positive impact on private investment, thereby increasing the level of economic growth in the areas these networks pass through (Matas et al., 2018). 
In Greece, the 1987-2007 period is mainly characterized by the construction of large-scale road projects co-financed by European funds and the entry of private capital into the construction and operation of infrastructure (Skagiannis and Kaparos, 2013).

The geography of Greek transport infrastructure is shaped by the influence of historical, economic, political and geomorphological factors and often reflects and / or contributes to the development potential and organization of the spatial network. The trunk road network (including the PATHE axis ${ }^{1}$ ) is spatially identified with the socalled "developmental S". This "developmental S" (taking its name from the S shape that it forms) links north, central and western Macedonia (Kavala and Thessaloniki) by means of the Egnatia motorway. It also links Macedonia and Thessaly (Volos and Larisa) with Athens and western Greece (Patra) through PATHE (Lambrianidis, 2001).

The degree to which road infrastructure projects generate favourable impacts and enhance regional development has become an increasingly controversial issue. Vickerman et al. (1999), for instance, observe that regional development policies aimed at the creation of infrastructure in lagging regions of Europe have not been very successful in reducing regional disparities. Petrakos and Saratsis (1999) investigated the impact of the creation of regional transport infrastructure on the rate of growth of GDP per capita and found no significant effect. Ioannides and Petrakos (2002) claim that the existence of good infrastructure is associated with higher levels of development, but it does not ensure further improvement, since this depends on additional economic and structural factors. Polyzos (1998) estimates that the impact of transport infrastructures can be positive or negative and that the geographical location (central or peripheral) along with the dynamics of the economy of each region are the key features that determine the "direction" of spatial impacts.

\footnotetext{
${ }^{1}$ PATHE stands for Patras-Athens-Thessaloniki and is a trans-European corridor offering high speed transport with double electrified lines and signaling.
} 


\section{Materials and methods}

\subsection{The operational program "Eastern Macedonia and Thrace 2007-} 2013"

The ROP "Macedonia-Thrace 2007-2013",2, deployed its developmental interventions in one specific territorial section, namely Macedonia and Thrace, which consists of three administrative regions: western Macedonia, central Macedonia and eastern Macedonia and Thrace. The eastern Macedonia and Thrace Region faces a greater development deficit so the operational program is focused on options and strategies that would ensure a high GDP growth rate in order to achieve convergence towards the country average. The development vision for eastern Macedonia and Thrace was divided into three general goals:

- Strengthening the competitiveness of the production system by utilizing the multiple possibilities offered by the transition to a knowledge-based economy.

- Utilization of its position in southeast Europe and the Balkans in particular, as well as its proximity to the emerging markets of the Black Sea and the Eastern Mediterranean.

- Promoting balanced economic and social development in the context of sustainability, with the aim of reducing inequalities and ensuring that everyone benefits from the results of development.

In order to achieve these goals, the program was structured around a number of priority axes (PA), four of which are presented in Figure 1:

\footnotetext{
${ }^{2}$ Approved by No. E (2007) 5337 26-10-2007 (CCI 2007 GR 161 PO 008) decision of the European Commission.
} 


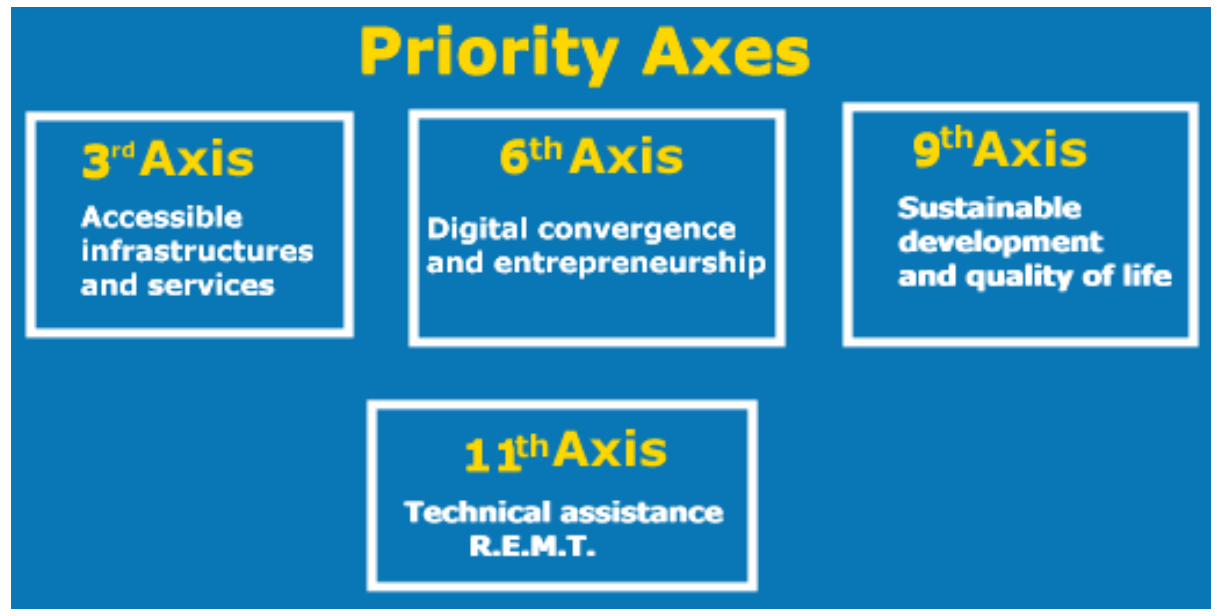

Figure 1: Four priority axes of the Operational Program

Source: http://oldsite.eydamth.gr/component/content/article/9-uncategorised/347-2009-08-04-2121-14.html)

This paper focuses on priority axes 3 and 9-which include interventions in the region's road network with a view to improving access to developed and developing sites of economic activity (industrial zones and ports) and to mountainous and remote areas. Other interventions are aimed at developing port infrastructures mainly in the cities of Alexandroupoli and Kavala as well as the completion of the railway network and its connection to sites of economic interest (i.e. industrial areas and ports).

Finally, one of the central objectives of the axes is to additionally complement the construction of the core national road network traversing the area, in parallel with the operation of new transport routes and the upgrade and modernization of border stations. The latter constitute an important component for the region under study since they ensure the prospect of exploiting the country's northeastern land border, which is of increased geopolitical importance in the context of EU enlargement in the east Balkans.

The principal interventions that took place under priority axes 3 and 9 relate to:

- Improvement/completion of the national and provincial road network and increase of accessibility to mountainous and remote areas.

- Completion of sections of the Egnatia highway and connection with ports and airports. 
- Strengthening of port infrastructures and connection of ports with transport networks.

- Improvement/completion of the railway network and linking it to sites of economic interest (industrial areas and ports).

- Improvement/construction of new border stations.

The interventions listed above were materialized by means of 87 projects whose total budget amounted to $€ 177,198,138.98$, the largest portion of which was received from EU funds with the remaining being Greece's contribution. Table A1 in the Appendix provides an overview of the amounts allocated for each project.

\subsection{Methods and data}

\subsubsection{Data collection process}

The data used for the realization of this research were mainly acquired from various public services in the region of eastern Macedonia and Thrace, and in particular:

(a) The Directorates of Technical Works in the regional units (RUs) of Evros, Rodopi, Xanthi, Kavala and Drama.

(b) The Intermediate Managing Authority (IMA) of the operational program "Eastern Macedonia - Thrace 2007-2013".

(c) The Directorate of Planning and Development in the region of Eastern Macedonia and Thrace.

(d) The transparency program.

(e) Central Electronic Public Procurement Registry (National Electronic Public Procurement System - NEPPS). 


\subsubsection{Research area}

The R.E.M.\&T occupies the northeastern extreme part of the country, bordering Turkey to the east, Bulgaria to the north and the region of central Macedonia to the west, while its southwest and southeast borders are the Aegean Sea and the Thracian Sea, respectively. The total area of the region amounts to 14,157 square kilometers, which corresponds to $10.7 \%$ of the total area of the country. The permanent population of the region, according to the provisional results of the 2011 Census, stands at 608,182 inhabitants, representing $5.6 \%$ of the total population of the country (Greek Statistical Authority ELSTAT, 2018). The region consists of five RUs, viz. Evros, Rodopi, Xanthi, Kavala and Drama. RUs are administrative units of Greece; they are subdivisions of the country's 13 regions, and can be further subdivided into municipalities. The population and spatial distribution by RU is described in the following table (Table 1).

Table 1: Area and population per regional unit and municipality

\begin{tabular}{lcccc}
\hline $\begin{array}{l}\text { REGIONAL UNIT / } \\
\text { MUNICIPALITY }\end{array}$ & $\begin{array}{c}\text { AREA } \\
\left(\mathbf{k m}^{2}\right)\end{array}$ & $\begin{array}{c}\% \\
\text { OF THE TOTAL } \\
\text { AREA OF } \\
\text { R.E.M.\&T. }\end{array}$ & POPULATION & $\begin{array}{c}\% \\
\text { OF THE TOTAL } \\
\text { POPULATION IN } \\
\text { R.E.M.\&T. }\end{array}$ \\
\hline R.U. EVROS & 4.242 & $29.96 \%$ & 147.947 & $24.33 \%$ \\
R.U. RODOPI & 2.543 & $17.96 \%$ & 112.039 & $18.42 \%$ \\
R.U. XANTHI & 1.793 & $12.67 \%$ & 111.222 & $18.29 \%$ \\
R.U. KAVALA & 2.111 & $14.91 \%$ & 138.687 & $22.80 \%$ \\
R.U. DRAMA & 3.468 & $24.50 \%$ & 98.540 & $16.16 \%$ \\
\hline TOTAL R.E.M.\& T. & $\mathbf{1 4 . 1 5 7}$ & $\mathbf{1 0 0 . 0 0 \%}$ & $\mathbf{6 0 8 . 1 8 2}$ & $\mathbf{1 0 0 . 0 0 \%}$ \\
\hline
\end{tabular}

Source: Greek Statistical Authority (ELSTAT).

From the information provided by the Directorate of Technical Works of each $\mathrm{RU}$, it can be seen that the national road network of the eastern Macedonia and Thrace Region amounts to a length of 1,054.00 kilometers in total, while the provincial road network equals 2,252.80 kilometers, i.e. approximately twice the size of the national road network. According to data gathered from the Greek Statistical Authority (EL.STAT.), the relationship between the length of the provincial and national road network, and GDP per RU is given in Table 2. 
Table 2: Length of provincial and national road network and GDP per RU of R.E.M.\&T. (in parentheses the percentage $\%$ share in the whole region)

\begin{tabular}{lccc}
\hline REGIONAL & PROVINCIAL & NATIONAL ROAD & GDP 2015 \\
UNIT & ROAD & NETWORK (Km.) & (EUR MIL.) \\
& NETWORK & & \\
& $($ Km.) & & 1,785 \\
EVROS & 571,00 & & $(26.41 \%)$ \\
& $(25,35 \%)$ & $366,00(34.72 \%)$ & 1,070 \\
RODOPI & 724,00 & & $(15.82 \%)$ \\
& $(32,14 \%)$ & $73,00(6.93 \%)$ & 1,073 \\
XANTHI & 243,80 & & $(15.87 \%)$ \\
& $(10,82 \%)$ & $144,00(13.66 \%)$ & 1,798 \\
KAVALA & $(20,11 \%)$ & $226,00(21.44 \%)$ & $(26.60 \%)$ \\
& 261,00 & & 1,034 \\
DRAMA & $(11,59 \%)$ & $245,00(23.24 \%)$ & $(15.30 \%)$ \\
\hline TOTAL & $\mathbf{2 . 2 5 2 , 8 0}$ & & $\mathbf{6 , 7 6 0}$ \\
R.E.M.\&T. & $(\mathbf{1 0 0 , 0 0 \% )}$ & $\mathbf{1 . 0 5 4 , 0 0 ( 1 0 0 . 0 0 \% )}$ & $(\mathbf{1 0 0 . 0 0 \% )}$ \\
\hline
\end{tabular}

\section{Results}

The outcomes of the current research are of particular interest as they show to a large degree the effect of road transport projects - executed pursuant to the ROP 2007-2013 for the R.E.M.\&T - on the development of the region. Furthermore, examination of interactions between the program funding and other important factors such as the area covered, the length of the road network improved, the type of roads (national, provincial or municipal) rehabilitated, the population, and the GDP reveals important information. For this purpose, correlation analysis has been performed utilizing Pearson's correlation coefficient. The statistical significance of the obtained correlation coefficients has been tested. Caution, however, should be applied in generalizing the statistical significance outcomes through p-value due to the small sample size. To export results, the IBM SPSS program 21 (Released IBM Corp., 2012) has been utilized. For the representation of the obtained results, scatter 
diagrams as well as the coefficient of linear correlation which gives the size of linear correlation between two variables have been used.

\subsection{Correlation of public expenditure and RUs}

As mentioned above, the research area consists of the RUs of Evros, Rodopi, Xanthi, Kavala and Drama, in which a total of 87 projects were completed in the time period under study. The number of projects allocated per RU are the following:

RU Evros: 17 (19.54\%), RU Rodopi: 16 (18.39\%), RU Xanthi: 14 (16.09\%), RU Kavala: 21 (24.14\%), RU Drama: 19 (21.84\%).

The total public investment (in million euros) per RU is as follows: RU Evros: 88.92, RU Rodopi: 24.99, RU Xanthi: 16.66, RU Kavala: 12.84, RU Drama: 33.78.

As can be seen, despite the fact that the RUs of Evros and Rodopi have approximately the same number of projects (17 and 16, respectively), the total budget for the roadworks performed in the RU of Evros is nearly quadruple. Regarding the total project funds received by the RUs, the RU of Evros occupies first position followed by the RU of Drama, 3rd place is occupied by the RU of Rodopi followed by the RU of Xanthi and lastly, 5th position is taken by the RU of Kavala. In addition, as regards the expenditure on all projects (being executed in every RU by all final beneficiaries from the region and the municipalities), it is noted that the funds were allocated proportionally according to the size of the RUs in terms of covered area. Thus, it is natural to expect a positive correlation between public expenditure and the total covered area.

\subsection{Correlation of public expenditure with projects and area of municipalities}

\subsubsection{Correlation of total public expenditure with projects per municipality and area of municipality}

The 87 road rehabilitation projects carried out under the ROP framework for eastern Macedonia and Thrace spatially correspond to a total of 21 municipalities. Table A1 in the Appendix demonstrates the total public expenditure on projects executed per municipality. In the diagram below (Figure 2), the two examined variables are the total public expenditure on projects carried out in each municipality (vertical axis) and the size of the municipality (horizontal axis). 


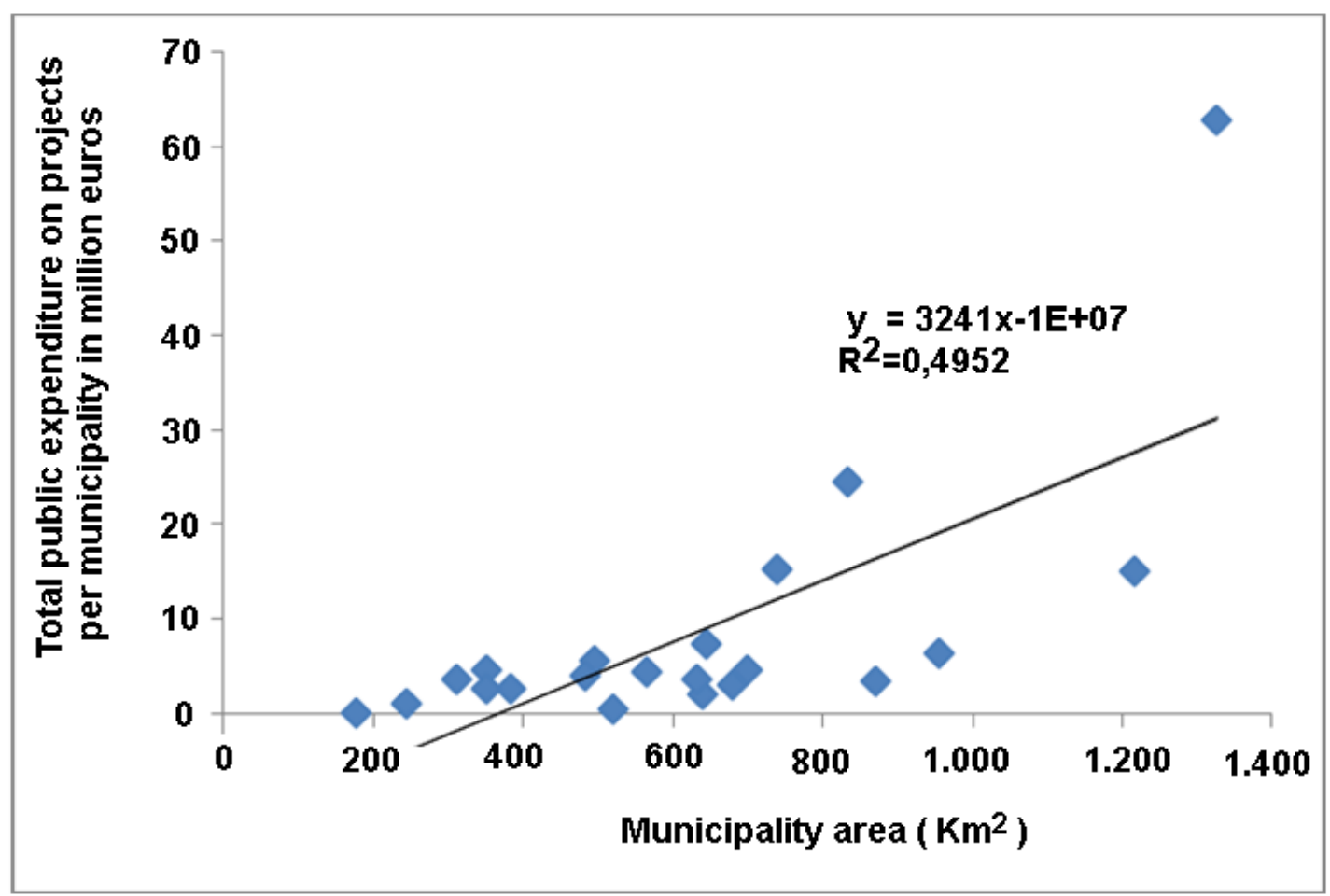

Figure 2: Total amount of public expenditure on projects per municipality - area of municipality

By observing the scatter diagram above it appears that there is a proportional relationship between the total amount of public expenditure on projects per municipality and the municipality area. Pearson's correlation coefficient $r$ has a value of 0.704 ( $\mathrm{p}$-value< 0.001 ), which indicates a positive correlation between the two variables.

4.2.2 Correlation of total public expenditure with projects and area levels of municipalities

The following table (Table 3) illustrates the public expenditure per municipal area classes (ranges: $200 \mathrm{~km}^{2}$ ): 
Table 3: Total public expenditure per class of municipality area

\begin{tabular}{lcc}
\hline $\begin{array}{c}\text { AREA CLASSES } \\
\left(\mathbf{k m}^{\mathbf{2}}\right)\end{array}$ & $\begin{array}{c}\text { NUMBER OF } \\
\text { PROJECTS }\end{array}$ & $\begin{array}{c}\text { PUBLIC EXPENDITURE } \\
(\boldsymbol{\epsilon})\end{array}$ \\
\hline $1^{\text {st }}: 0-200$ & 1 & $125,104.00$ \\
$2^{\text {nd }}: 201-400$ & 12 & $14,593,069.15$ \\
$3^{\text {rd }}: 401-600$ & 13 & $14,404,172.86$ \\
$4^{\text {th }}: 601-800$ & 34 & $35,867,255.39$ \\
$5^{\text {th }}: 801-1000$ & 18 & $34,321,770.04$ \\
$6^{\text {th }}: 1001$ and up & 9 & $77,886,767.54$ \\
\hline
\end{tabular}

A graphical representation of the table above is shown in Figure 3 where we can easily observe the relatively good proportionality of public expenditure from class to class. The two variables that are studied using Pearson's coefficient are the amount of public expenditure on the projects and area classes of municipalities.

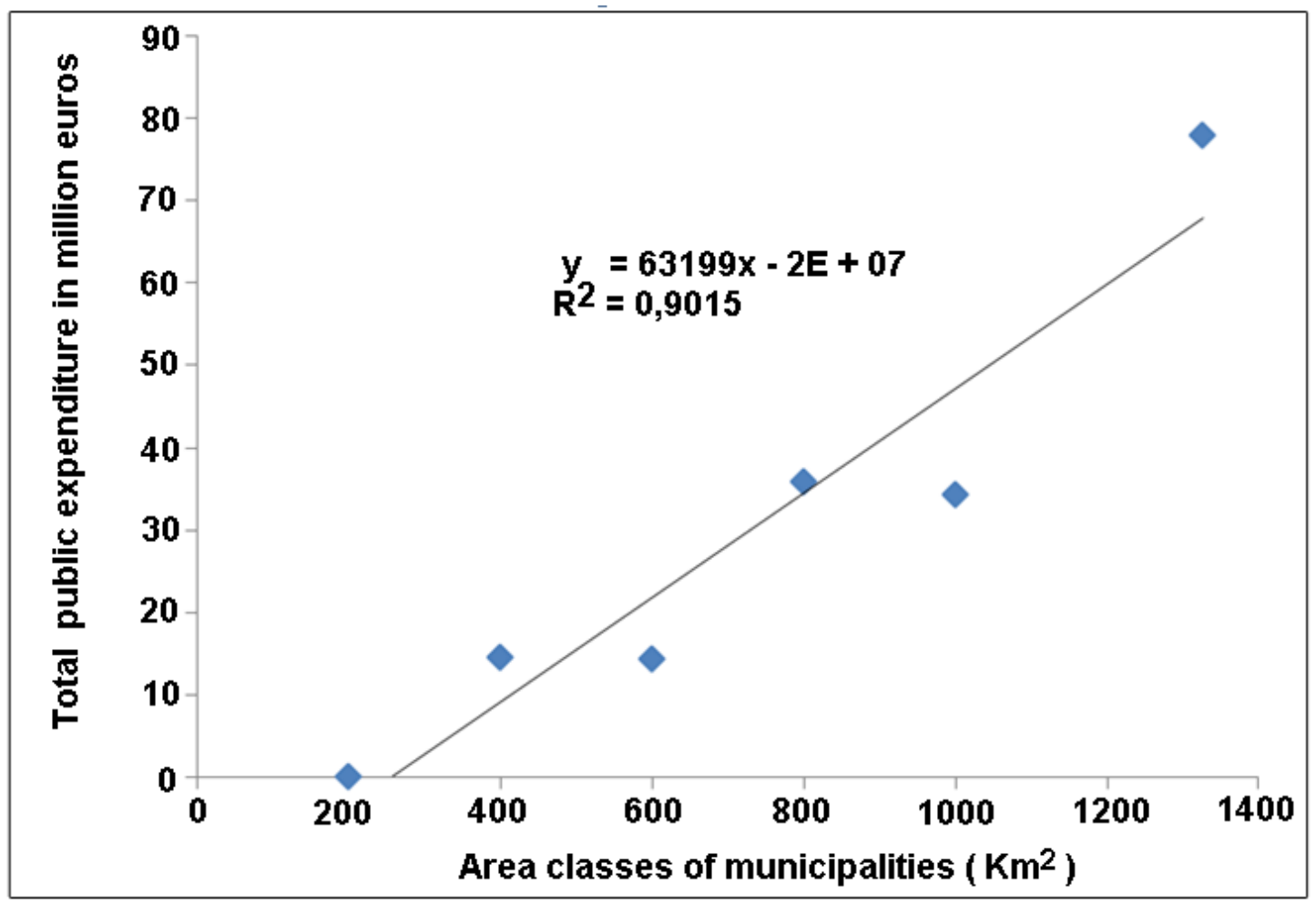

Figure 3: Total public expenditure on projects - area classes of municipalities

From the scatter diagram above it is apparent that there is a proportional correlation between the amount of the total public expenditure and the municipalities 
whose total area falls within the range limit of $200 \mathrm{~km}^{2}$. The correlation coefficient has a value of 0.949 ( $\mathrm{p}$-value $=0.004<0.01)$, therefore there is a very strong positive correlation between the two variables, statistically significant at the $1 \%$ significance level.

\subsection{Correlation of public expenditure and improved road network length}

\subsubsection{Correlation of public expenditure with projects and municipal road network length that improved}

In the diagram below (Figure 4) the horizontal axis shows the length of municipal roads improved and the vertical axis the amount of public expenditure on projects.

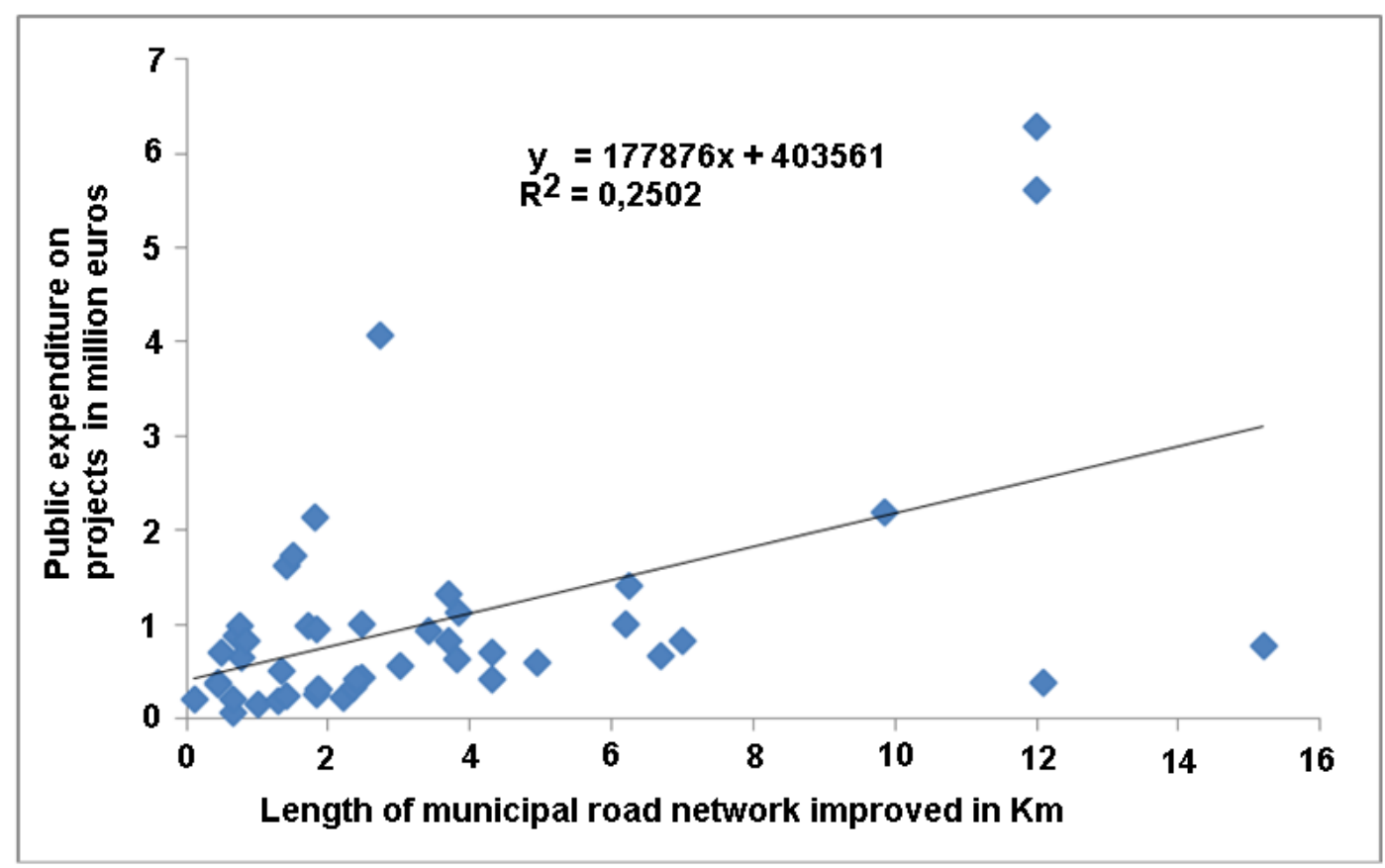

Figure 4: public expenditure and length of municipal road network improved by project implementation

From the scatter diagram above it appears that there is a proportionate relationship between the amount of public funds allocated for the projects and the length of the municipal road network improved. The correlation coefficient $r$ has a 
value of 0.5 (p-value $<0.001$ ), indicating that there exists a statistically significant correlation between the two variables.

\subsubsection{Correlation of public expenditure with projects and provincial road network length improved}

Out of the total of 87 projects carried out, 33 are concerned with interventions aiming at rehabilitating the provincial road network of the region. The two variables examined here are the amount of public expenditure on the 33 projects and the length of provincial road network improved with their implementation (Figure 5).

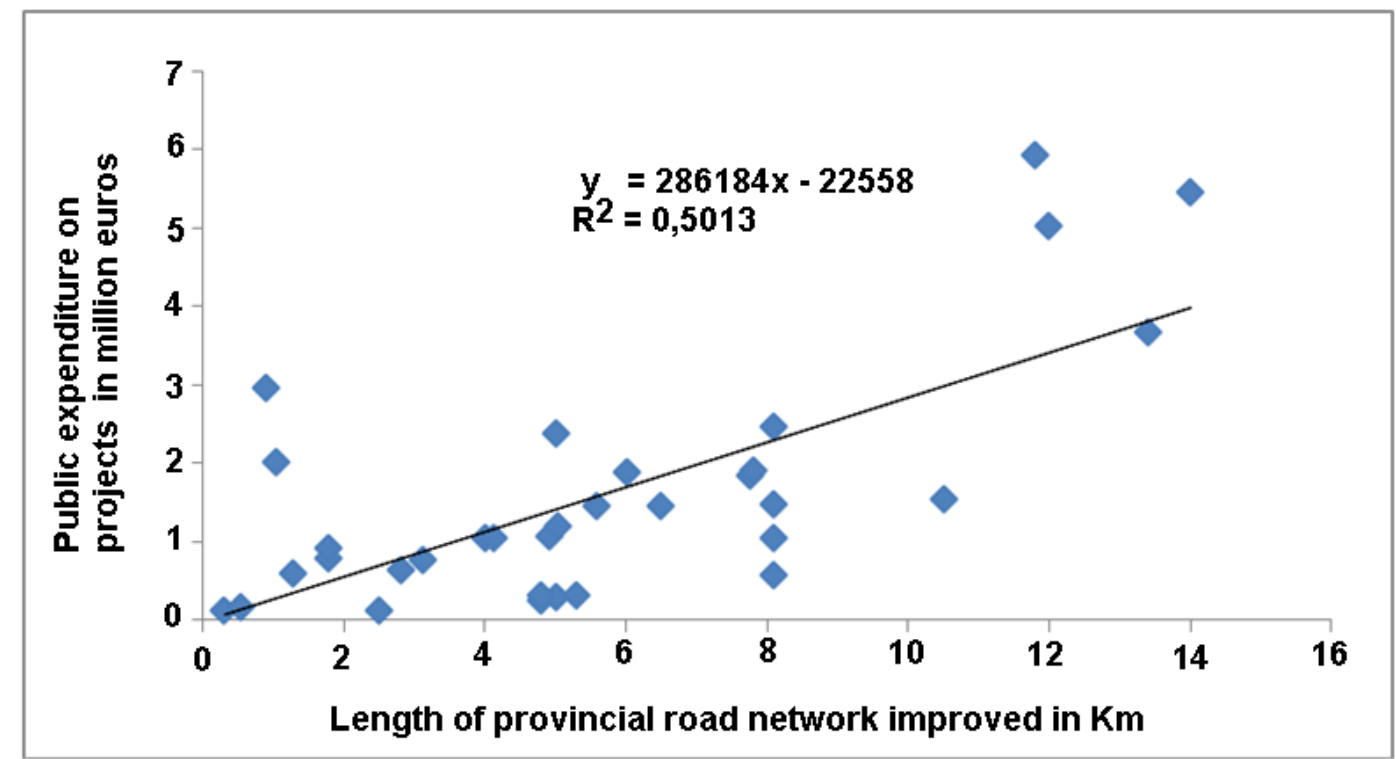

Figure 5: public expenditure on projects and length of provincial road network that improved with their implementation

The correlation coefficient $\mathrm{r}$ is 0.708 ( $\mathrm{p}$-value $<0.001$ ), which shows a strong correlation between the two variables. Hence, it has been found that there is a strong and positive interaction between public expenditure on the 33 projects relating to the rehabilitation of the provincial road network and the corresponding length in kilometers of provincial roads reconstructed.

\subsubsection{Correlation of public expenditure with projects and length of national road network that improved}

From our sample, 8 projects are concerned with interventions aiming at improving the national road network of the region. The two variables that are studied 
this time are the amount of public expenditure on the eight projects and the length of the national road network improved through their execution.

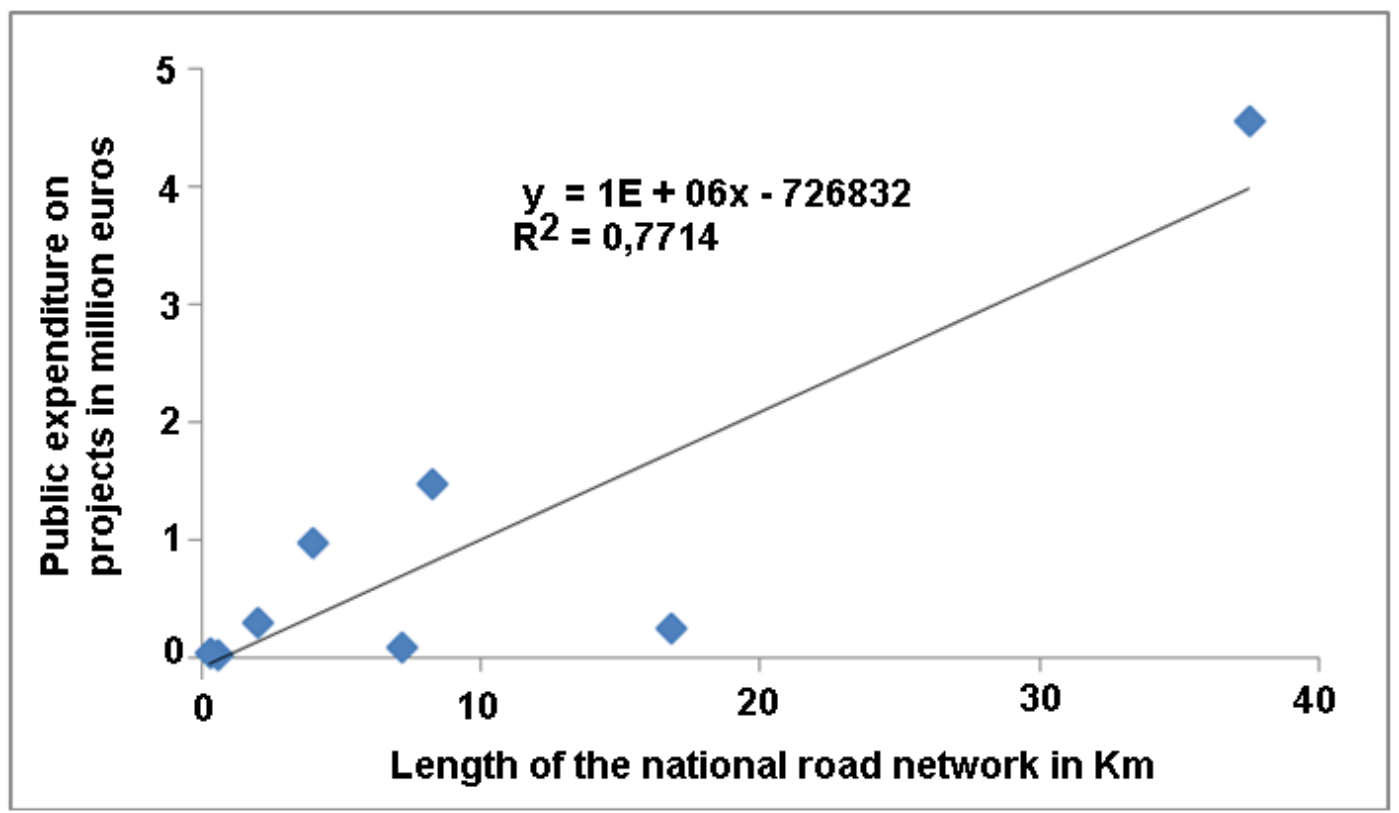

Figure 6: public expenditure on projects and length of national road network improved with their implementation

From the above scatter diagram (Figure 6) it appears that there is a proportional correlation between the amount of public expenditure and the length of the national road network improved. The correlation coefficient $\mathrm{r}$ is $0.878(\mathrm{p}-$ value $=$ $0.004<0.01)$ so there is a very strong positive correlation between the two variables.

\subsubsection{Correlation of public expenditure with projects per municipality and length of road network improved per municipality}

Table A1 in the Appendix illustrates the total public expenditure on roadworks per municipality and the total (per municipality) length of roads (in kilometers) improved through the implementation of the projects, with the name of the municipalities in alphabetical order. In the diagram below (Figure 7) the horizontal axis shows the total length of road network rehabilitated (it includes all kinds of roads - municipal, provincial and national) and the vertical axis the amount of total public expenditure on projects per municipality. 


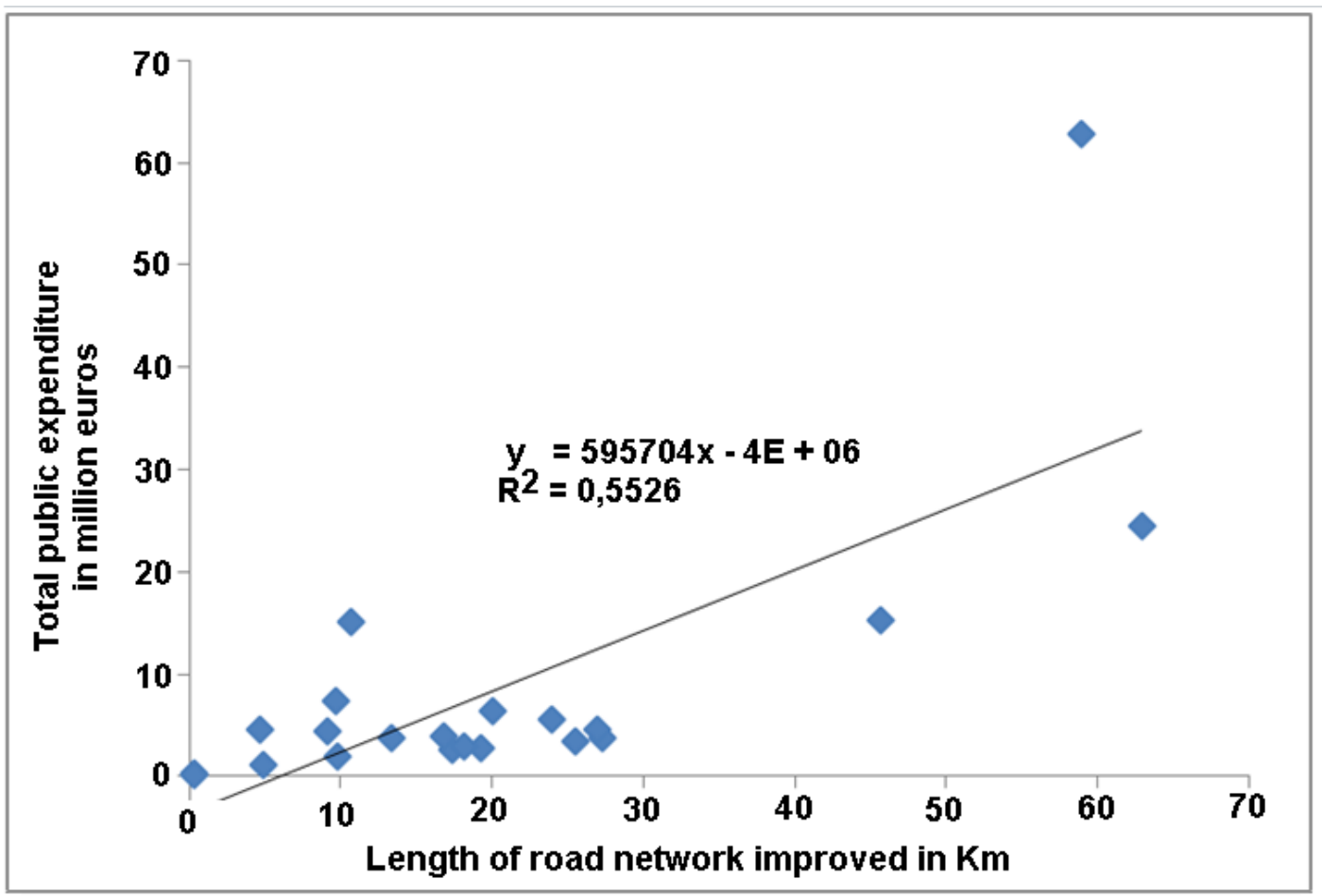

Figure 7: Public expenditure on projects - length of road network that improved with their implementation

Correlation coefficient $r$ has a value of 0.743 ( $\mathrm{p}$ value $<0.001$ ), Hence, it is apparent that there exists a considerably strong linear correlation between the total amount of public expenditure on all roadwork projects executed in the 21 municipalities and the total length (in kilometers) of roads that were rehabilitated in these municipalities.

4.4 Correlation of public expenditure with projects per municipality and population of municipality

In this section we examine the relationship of another set of variables: public expenditure on roadwork projects per municipality and the population of the municipality (see Figure 8). 


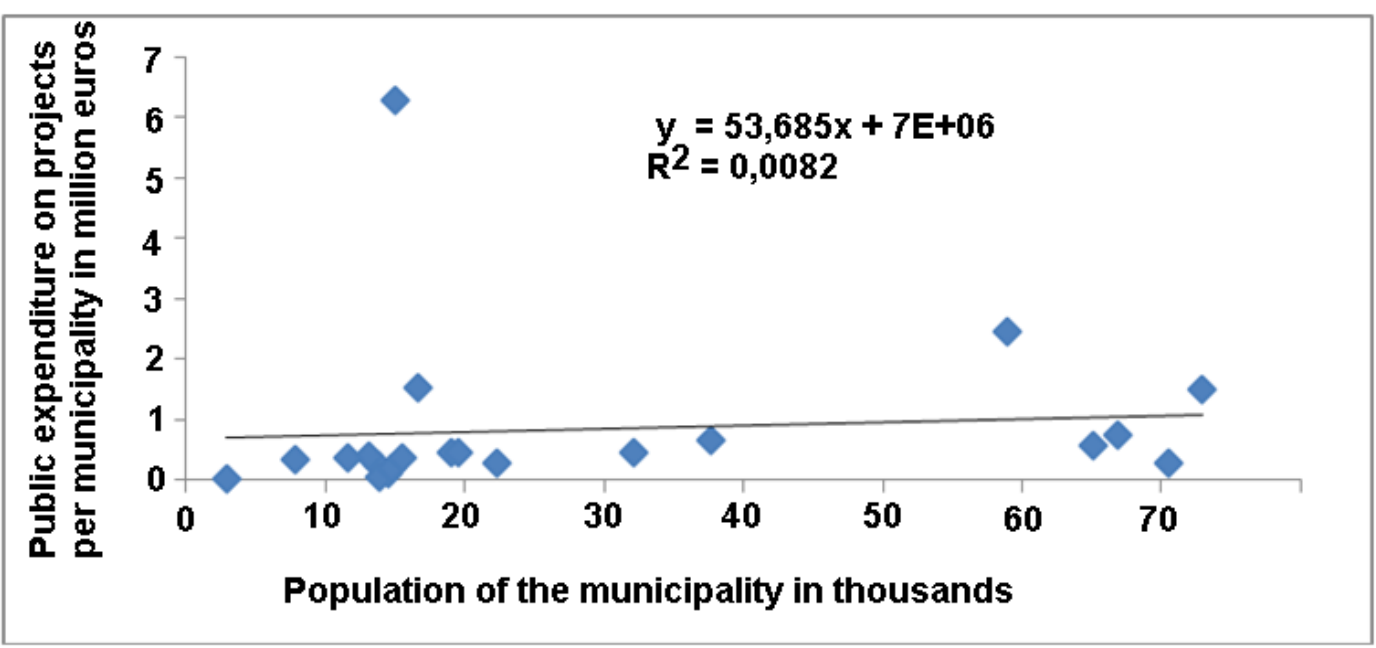

Figure 8: Public expenditure per municipality and population of the municipality

Correlation coefficient $r$ for the association between the two variables is 0.090 ( $\mathrm{p}$ - value $=0.697>0.05)$ so there is almost a zero correlation between the two variables.

\subsection{Correlation of public expenditure and gross domestic product (GDP)}

The two variables to be examined here are the total public expenditure on roadwork projects and the GDP of each RU in eastern Macedonia and Thrace. Table 4 below presents the total public expenditure on projects per RU:

Table 4: Total public expenditure and GDP per RU

\begin{tabular}{lcc}
\hline $\begin{array}{l}\text { REGIONAL } \\
\text { UNIT }\end{array}$ & $\begin{array}{c}\text { PUBLIC EXPENDITURE (EUR } \\
\text { MIL.) }\end{array}$ & $\begin{array}{c}\text { G.D.P. PER R.U. } \\
\text { (EUR MIL.) }\end{array}$ \\
\hline EVROS & & \\
RODOPI & 88,92 & 1.785 \\
XANTHI & 24,99 & 1.070 \\
KAVALA & 16,66 & 1.073 \\
DRAMA & 12,84 & 1.798 \\
\hline
\end{tabular}

In the diagram below (Figure 9), the horizontal axis represents the GDP of each RU and the vertical axis the total amount of public expenditure on projects per RU. 


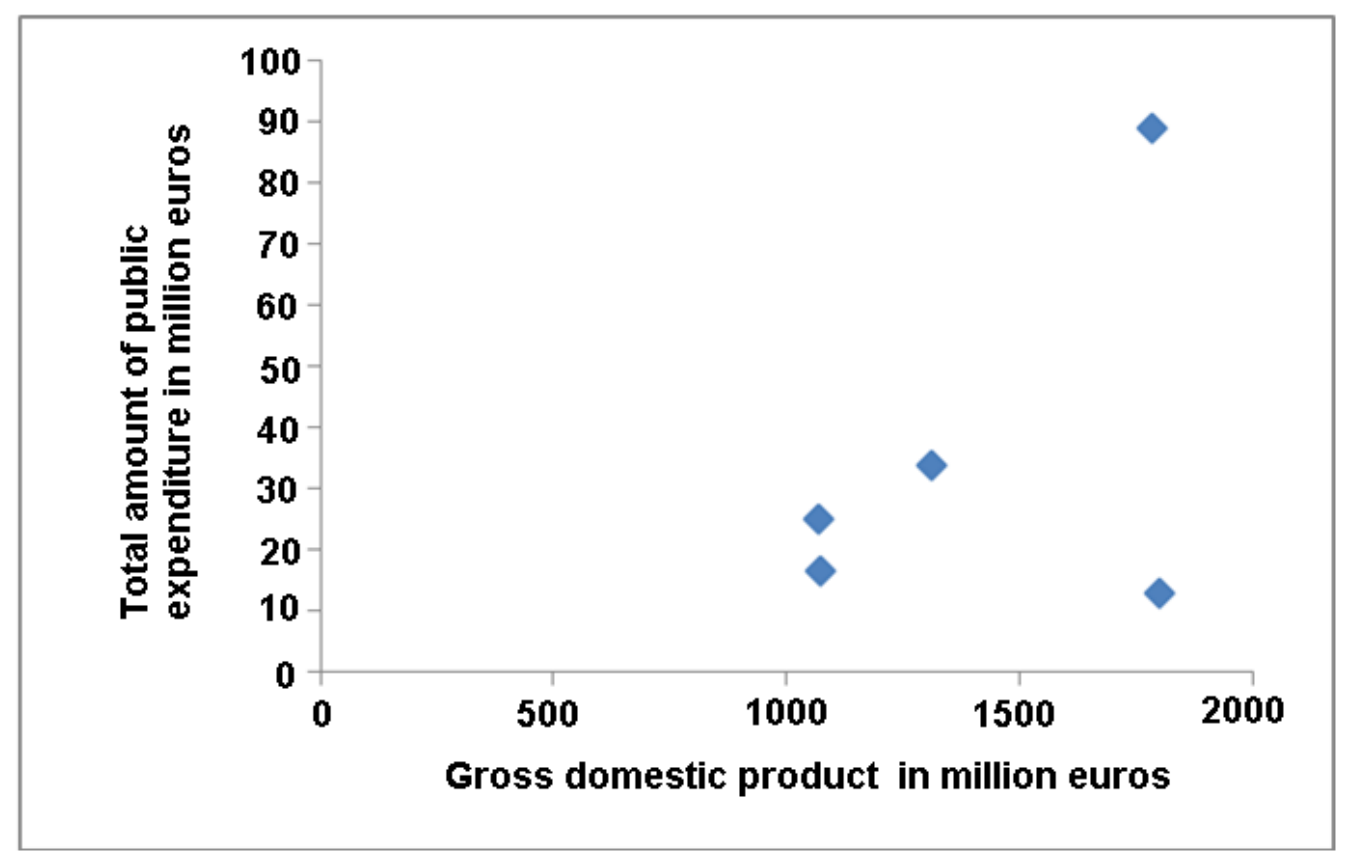

Figure 9: Contractual public expenditure per RU and GDP per RU.

Due to the limited sample related to the two variables, we do not report the correlation coefficient for this association; however, inspection of the scatterplot indicates a lack of dependence between the total amount of public expenditure and GDP.

\section{Discussion and conclusions}

The aim of this research is to examine how and in which areas the road transport projects carried out under the framework of the NSRF 2007-2013, contributed to the economic development of a Greek region, viz. the region of Eastern Macedonia and Thrace. The program involved a total of 87 road projects that were implemented with a total investment of $€ 177,198,138.98$. Approximately $70 \%$ of this amount was jointly allocated to the RUs of Evros and Drama, with the RU of Evros absorbing around $50 \%$ of that budget. These two spatial entities occupy the two extreme parts of the region of eastern Macedonia and Thrace, and the high allocation of public funds on roadworks in these two administrative districts aimed to assist in their integration within the wider economic context of the region. 
It is clearly seen that the RU of Evros includes the highest percentage (34.7\%) of national road network in the Thrace part of the R.E.M.\&T. Additionally, the Evros road network had barely been improved in the years preceding the materialization of the road transport projects. Due to this fact, the Evros RU received more public funds, as the construction requirements of the national road network traversing the RU were undoubtedly higher and more costly. In contrast, other RUs, due to an already existing well-maintained national road network, had clearly lower construction requirements and, therefore, incurred lower costs.

One of the main conclusions of the current study is that the public expenditure on the 87 projects is in direct correlation both with the area of the municipalities and the length of the road network improved, whereas there is no correlation with the municipal population or the GDP in each RU. Therefore, the size of the area of each municipality is a reliable indicator of the extent of the road network constructed or rehabilitated. In other words, the larger the area of the municipality, the greater need exists for improvement and modernization of road infrastructures. For instance, the municipality of Soufli, which is the largest in area $\left(1,326.00 \mathrm{~km}^{2}\right)$ of the RUs, absorbed up to $35 \%$ of the total amount of public expenditure, while the municipality of Samothraki, which is the smallest in size, received the lowest amounts of public funds.

The length of road network rehabilitated with the execution of the 87 roadwork projects also directly correlates with the size (and the allocation) of public investment. In particular, a total of 425.3 kilometers of road network have been upgraded and reconstructed, of which $161.7 \mathrm{~km}$ are classified as a municipal road network, $186.7 \mathrm{~km}$ as a provincial road network and $76.7 \mathrm{~km}$ as a national road network. Public funding has been calculated to provide $27 \%$ of resources for municipal roads, $30 \%$ for provincial roads and $43 \%$ for national roads.

The results of the current study clearly demonstrate that the NSRF 2007-2013 road transport projects have substantially contributed to the development of the region in a unified way, through improving existing accessibility, upgrading accessibility, and most importantly, through the expansion of municipal, provincial and national road networks in all areas, in those with an uneven geomorphological relief.

The correlation between the length of municipal, provincial and national road networks on one hand and public expenditure on the other, has been found to be positive and statistically significant. More specifically, there is a positive relationship 
between public investment and the length of the municipal and provincial road networks improved. There is also a particularly strong positive interaction between public investment and the length of the national road network rehabilitated. Hence, it is evident that more emphasis has been placed towards refining the national road network of the region. It is important to note that the national network is closely related to the Egnatia highway and its connection with the most isolated locations of the region as well as with ports and airports. We may deduce then, that in general, there has been a balanced development and improvement of road networks with the aim of boosting road connectivity, reducing isolation of some localities, linking the most isolated districts to the centers of the R.E.M.\&T., developing mountainous areas and reducing intra-regional inequalities. A future anticipated outcome could be generating income and fueling employment by reducing the cost and time for transporting people and goods and raising the level of services. According to previous research, improving national road networks reduces spatial inequalities, changes geographic accessibility, increases interactions, cooperation, economic exchanges and competition, boosts overall mobility, and generally, changes the existing spatial balance at both economic and social levels (Polyzos, 1998). Finally, as a suggestion to policy makers responsible for the region under study, it is recommended that future interventions related to road infrastructure construction and development should be targeted at the improvement of the rest of the regional (non-national) road network, in order to enhance the impact of the previous interventions and promote development.

With regard to the relationship between public expenditure and the municipal population, the 87 road projects of the program are not correlated with the population of the 21 municipalities in which they were executed. This is an anticipated finding, since the allocation of projects is influenced by other factors such as urbanity or the mountainous landscape of the municipalities. For instance, small in size municipalities such as the municipality of Kavala, have a large population due to their urbanity, as opposed to the municipality of Soufli, which, while being the largest municipality in size, has a small population owing to certain characteristics, such as its mountainous character and distance from main urban centers.

The above findings suggests that efficient allocation of infrastructure resources in a region by policy makers should not be directly influenced by a single characteristic such as the regional population density. Decisions should be based on more complex considerations, such as existing natural resources, geomorphological 
characteristics and geographic location of the region, as well as the competitive advantages of improved interconnections between the specific region and neighboring regions.

As a general conclusion based on the results of the current research, it is suggested that emphasis should be given empowering regions with the execution of more road projects in order to enhance their attractiveness, and promote cohesion, entrepreneurship and innovation. In pursuit of this goal, the simplification of the institutional framework for the integration of road works may significantly assist. The continuation of road projects may also establish a culture of training among employees. This will, ultimately, help tackle the difficulties caused by shortage of qualified personnel, incomplete training of managers responsible for project implementation, lack of implementation experience observed in the already conducted co-financed operations and lack of familiarity on the part of the executives involved with the management and execution of the NSRF program.

The basic interventions required include improving the knowledge and skills of the human resources of the beneficiaries, in order to enable them to cope with the structural and institutional changes, with more emphasis placed on the training of middle and senior officials. Attention should also be paid to the revision of the program depending on the actual needs of a region instead of having to rely on the absorption of funds as the only driving motive. Moreover, greater attention needs to be paid to the transfer of resources towards transport infrastructure projects that can enhance regional attractiveness, social cohesion, entrepreneurship and innovation, especially under the changes currently occurring in the economic environment. Finally, the modernization of the public sector can contribute to the overall improvement of transport systems and the development of remote areas. Such modernization can be achieved by increasing the efficiency, effectiveness and performance of public services and restricting central bureaucratic procedures as well as by promoting the cooperation of local authorities - regional and ministerial - in generating a better awareness of local problems.

\section{Declaration of competing interest}

The authors declare that they have no known competing financial interests or personal relationships that could appear to influence the work reported in this paper. 


\section{References}

Akyelken, N. (2015) 'Infrastructure Development and Employment: The Case of Turkey'. Regional Studies, volume 49, issue 8, pages 1360-1373.

Antonescu, D. (2014) 'Regional development policy in context of Europe 2020 Strategy'. Procedia Economics and Finance, volume 15, pages 1091 - 1097.

Aschauer, D.A. (1989) 'Is public expenditure productive?' Journal of Monetary Economics, volume 23, issue 2, pages 177-200.

Begg, I. (2010) 'Cohesion or Confusion. A Policy Searching for Objectives'. Journal of European Integration, volume 32, issue 1, pages 77-96.

Biehl, D. (1991) 'The role of infrastructure in regional development'. In Vickerman, R.W. (ed.), Infrastructure and regional development. Pion, London, UK.

Cosci, S. and Mirra, L. (2018) 'A spatial analysis of growth and convergence in Italian provinces: the role of road infrastructure'. Regional Studies. Volume 52, issue 4, pages 516-527.

Crescenzi, R. and Rodríguez-Pose, A. (2012) 'Infrastructure and regional growth in the European Union'. Papers in Regional Science, volume 91, issue 3, pages 487-513.

Dontigney, E., n.d. The Difference Between Top-Down and Bottom-Up Strategic Management. Available at: http://yourbusiness.azcentral.com/difference-betweentopdown-bottomupstrategic-management-17085.html [Accessed / Retrieved on 15-122017].

European Commission (2011) Roadmap for a Single European Transport Area. Brussels. European Commission.

Fallon, J. (1997) 'Privatising Public Infrastructure: Rationale and Key Issues'. Economic Analysis and Policy. Volume 27, issue 2, pages 175-189. 
Goletsis, Y. and Chletsos, M. (2011) 'Measurement of development and Regional disparities in Greek periphery: A multivariate approach'. Socio-Economic Planning Sciences, volume 45, pages 174- 183.

Hadjiioannou, Th. (2015) 'Transport Infrastructure and Regional Development: Examples from the Attica Highway'. Postgraduate Thesis. School of Architecture, NTUA. Athens (in Greek).

Hoerner, J. and Stephenso, P. (2012) 'Theoretical perspectives and approaches to Policy Evaluation in EU: The case of cohesion Policy'. Public Administration - Wiley Online Library.

IBM Corp. Released (2012) IBM SPSS Statistics for Windows, Version 21.0. Armonk, NY: IBM Corp.

Ioannides, Y.M. and Petrakos, G. (2000) 'Regional disparities in Greece: The performance of Crete, Peloponnese and Thessaly'. EIB Papers, ISSN 0257-7755, European Investment Bank (EIB), Luxembourg, volume 5, issue 1, pages 30-58.

Matas, A., Raymond, J-L. and Ruiz, A. (2018) 'Regional infrastructure investment and efficiency'. Regional Studies, volume 52, issue 12, pages 1684-1694.

Mikulic, D., Lovrincevic, Z. And Nagyszombaty, A.G. (2013) 'Regional Convergence in the European Union, New member states and Croatia'. South East European Journal of Economics and Business, volume 8, issue 1, pages 7-19.

Monastiriotis, V., Crescenzi, R. and Fratesi, U. (2017) 'The EU cohesion policy and the conditioning success and failure: evidence from 15 Regions'. Regions Magazine, volume 305 , issue 1 , pages. $4-7$.

Moya-Gómez, B and Geurs, K. 'The spatial-temporal dynamics in job accessibility by car in the Netherlands during the crisis'. Regional Studies, forthcoming 
Petrakos, G. (2004) 'Regional inequalities and Regional Policy in Greece'. Aichoros, volume 8 , Issue 1 , pages 6 - 31 .

Petrakos, G. and Saratsis, G. (2000) 'Regional Inequality in Greece'. Papers in Regional Science, volume 79, pages 1-18.

Petrakos, G. and Tsoukalas, D. (2004) 'The Metropolitan concentration in Greece: an empirical investigation, in D. Oikonomou and G. Petrakos'. The Development of Greek cities: interdisciplinary approaches for urban analysis and policy, University of Thessaly, Volos Gutenberg.

Petrakos, G. (2012) 'Integration, spatial dynamics and Regional policy dilemmas in the European Union. University of Thessaly, Discussion Paper Series, volume 18, issue 2 , pages $18-40$.

Petrakos, G. and Economou, D. (2014) 'Spatial Asymmetry in Southeastern Europe'. The journal of Economic asymmetries, volume 1, issue, pages 127-149.

Polyzos, S. (2011) 'Regional Development'. Athens: Kritiki (in Greek).

Polyzos, S (1998) 'Interregional road projects and their contribution to regional development: A theoretical and empirical investigation. Doctoral thesis. Department of Planning and Regional Development Engineering'. University of Thessaly. Volos, Greece (in Greek).

Rietveld, P. (1994) 'Spatial economic impacts of transport infrastructure supply'. Transportation Research Part A: Policy and Practice, volume 28, issue 4, pages 329341.

Rolfe, J and Flint, N. (2018) 'Assessing the economic benefits of a tourist access road: A case study in regional coastal Australia'. Economic Analysis and Policy, volume 58, pages 167-178. 
Skagiannis, P. and Kaparos, G. (2013) 'Infrastructure projects in Greece and the presence of major transport infrastructure projects: changing models and priorities'. Sustainability, volume 18, pages 12-65 (in Greek).

Stelder, D. (2016) 'Regional Accessibility Trends in Europe: Road Infrastructure, 1957-2012'. Regional Studies, volume 50, issue 6, pages 983-995.

Tvrdon, M. (2012) 'Cohesion Policy, Convergence and Regional Disparities: the Case of the European Union'. WSEAS transactions on business and economics - wseas.us.

Vickerman, R., Spiekermann, K. and Wegener, M. (1999) 'Accessibility and Economic Development in Europe'. Regional Studies. volume 33, issue 1, pages 1-15.

Zhang, Y-F. and Ji, S. (2019) 'Infrastructure, externalities and regional industrial productivity in China: a spatial econometric approach'. Regional Studies, volume 53, issue 8 , pages $1112-1124$. 


\section{APPENDIX}

Table A1: Total amount of public expenditure (European and national funds) on roadwork projects and total length of road network improved per Municipality area of Municipality

\begin{tabular}{|c|c|c|c|}
\hline MUNICIPALITY & $\begin{array}{c}\text { TOTAL AMOUNT OF } \\
\text { PUBLIC EXPENDITURE } \\
(€)\end{array}$ & $\begin{array}{c}\text { TOTAL } \\
\text { LENGTH } \\
\text { OF ROAD } \\
\text { NETWORK } \\
\text { IMPROVED } \\
(\mathbf{k m})\end{array}$ & $\begin{array}{c}\text { MUNICIPALITY } \\
\text { AREA }\left(\mathbf{k m}^{2}\right)\end{array}$ \\
\hline AVDIRA & $4,544,254.65$ & 4.63 & 352.00 \\
\hline ALEXANDROUPOLI & $15,112,468.47$ & 10.66 & $1,217.00$ \\
\hline ARIANNA & $15,274,615.90$ & 45.67 & 738.65 \\
\hline DIDYMOTECHO & $4,461,463.67$ & 9.13 & 565.40 \\
\hline DOXATO & $1,073,872.40$ & 4.90 & $244, .10$ \\
\hline DRAMA & $24,462,010.58$ & 62.88 & 833.01 \\
\hline THASSOS & $2,599,571.50$ & 17.36 & 383.00 \\
\hline IASMOS & $379,713.82$ & 0.30 & 519.34 \\
\hline KAVALA & $2,698,203.83$ & 19.25 & 350.61 \\
\hline KOMOTINI & $7,316,025.70$ & 9.62 & 644.90 \\
\hline MARONIA SAPES & $2,024,612.88$ & 9.73 & 640.11 \\
\hline MYKI & $3,713,875.68$ & 27.28 & 633.30 \\
\hline NESTOS & $2,963,800.41$ & 18.10 & 678.90 \\
\hline K.NEVROKOPI & $3,409,575.48$ & 25.53 & 870.00 \\
\hline XANTHI & $5,577,991.12$ & 23.98 & 495.10 \\
\hline ORESTIADA & $6,450,183.98$ & 19.98 & 955.60 \\
\hline
\end{tabular}




\begin{tabular}{lccc}
\hline PAGGAIO & $4,574,324.82$ & 26.95 & 698.01 \\
PROSOTSANI & $3,985,004.25$ & 16.76 & 482.77 \\
SAMOTHRAKI & $125,104.00$ & 0.30 & 178.00 \\
SOUFLI & $62,774,299.07$ & 58.88 & $1,326.00$ \\
TOPEIRO & $3,677,166.77$ & 13.39 & 312.49 \\
\hline
\end{tabular}

